\title{
Multicentre clinical trials in infectious diseases in Canada
}

$\mathrm{C}$ LINICAL TRIALS ARE AN IMPORTANT COMPONENT OF OPtimal timal medical practice. Comparative trials are the only means allowing an assessment between competing therapeutic options (1). Scientifically valid clinical trials which ask clinically meaningful questions and which are well-designed and appropriately executed may have a profound impact on clinical medicine. A few examples of such studies which immediately have influenced care in infectious diseases include the initial studies of vidarabine in herpes encephalitis (2), the efficacy of polio vaccine (3) and the primary prevention of rheumatic fever with penicillin for streptococcal pharyngitis (4). Most aspects of clinical practice, however, have not been validated by appropriate clinical trials.

Multicentre clinical trials are undertaken when one centre cannot enroll sufficient study subjects within a predetermined time frame to ensure scientific validity. A multicentre study increases the complexity of a clinical trial by requiring standardization of the study; this requires intensive monitoring and (usually) greatly increases cost.

Currently there is limited funding available to support clinical research. While some studies are funded through National Institutes of Health, National Health and Welfare Research and Development Program, local agencies and, less frequently, the Medical Research Council, the majority of multicentre clinical trials are funded through the pharmaceutical industry. Pharmaceutical sponsored studies may provide important insights. For antimicrobials, however, many are "off the mark' with respect to clinical appropriateness of therapeutic regimens being compared. This reflects the fact that such studies generally are undertaken to obtain licensing indications for a particular antimicrobial, not primarily to answer relevant clinical questions.

The Clinical Trials Subcommittee of the Canadian Infectious Diseases Society has promoted the development and execution of multicentre clinical trials within the Canadian Infectious Diseases Society for over 10 years. A number of publications have resulted from studies undertaken through the auspices of this subcommittee (5-10). The majority of these have been pharmaceutically funded studies, with some sponsored jointly with the National Cancer Institute of Canada. Important observations have been made by these studies. A persistent problem, however, is how to address the many important clinical issues in infectious diseases which, because they do not address questions relevant to a pharmaceutical marketing strategy, do not attract funding.

In this issue of the Journal, a collection of five workshop summaries from a clinical trials meeting of the Canadian Infectious Diseases Society in February 1991 is published (page 75). The goals of these sessions were to identify potential important questions relating to infectious diseases which could be answered through multicentre clinical trials in Canada. The workshop titles were not inclusive; they were selected as representative and important themes from which to develop limited objectives. The summaries - which demonstrate different approaches in different workshops - document the diversity of problems and the interests of the Canadian infectious diseases community.

A recurring theme through all of the workshops is the need for development of Canadian databases for infectious diseases. We rely heavily, almost exclusively in fact, on data generated primarily in the United States and occasionally Europe, and extrapolate this information to the Canadian theatre. Unique features in the epidemiology of infectious diseases in Canada, seasonal variations and funding of the health care system mean that this approach is not necessarily, or even usually, valid. Thus there was a general feeling that registries and other databases need to be developed to identify disease occurrence and manifestations of important infections in clinical practice in Canada. While the laboratory Centre for Disease Control, and provincial and territorial health departments fulfill some of this in 
surveillance of selected infections, the diseases identified by the public health surveillance network are generally uncommon (with the exception of sexually transmitted agents). What is the Canadian occurrence of prosthetic infections? Of disseminated fungal infections in granulocytopenic patients? Of brain abscess? One such database, describing retrospectively the use of ribavirin in pediatrics, has already been collected and presented (11). This report was the first outcome from this clinical trials meeting.

The February meeting was unquestionably a useful experience and enthusiastically supported by participants. The success of this meeting, however, will be measured by clinical trial development in Canada based on these discussions. The problems of funding for multicentre clinical trials, particularly in the current highly competitive research environment with limited funds available, and of committment by personnel who are already overcommitted remain. The workshop summaries, however, serve as indicators of the variety and complexity of, and the need for, multicentre clinical trials in infectious diseases in Canada. It is to be hoped that this Journal will have the opportunity to publish studies resulting from these discussions over the next several years.

These workshops were sponsored by a grant from Merck Frosst Canada Inc.

\section{REFERENCES}

1. LaForce FM. US Preventive Services Task Force. Immunizations, immunoprophylaxis and chemoprophylaxis to prevent selected infections. J Am Med Assoc 1987;257:2464-70.

2. Whitley RJ, Soong S-J, Dolin R, et al. Adenine arabinoside therapy of biopsy-proved herpes simplex encephalitis. NIAID collaborative antiviral study. N Engl J Med 1977;297:289.
3. Salk JE. Poliomyelitis: Control. In: Rivers TM, Horsfall FL Jr, eds. Viral and Rickettsial Infections of Man, 3rd edn. Philadelphia: Lippincott, 1959:499-518.

4. Denny FW, Wannamaker, LW, Brink WR, Rammelkamp $\mathrm{CH}$ Jr, Custer EA. Prevention of rheumatic fever: Treatment of the preceding streptococcal infection. J Am Med Assoc 1950;163:151-3.

5. Harding G, Vincelette J, Rachlis A, et al. A preliminary report on the use of ceftizoxime vs clindamycin/ tobramycin for the therapy of intra-abdominal and pelvic infection. J Antimicrob Chemother 1982;10 (Suppl C):191-2.

6. Mandell LA, Nicolle LE, Ronald AR, et al. A multicentre prospective randomized trial of ceftazidime versus cefazolin/tobramycin in the treatment of hospitalized patients with pneumonia. J Antimicrob Chemother 1987;20:95-107.

7. Feld R, Louie TJ, Mandell L, et al. A multicentre comparative trial of tobramycin and ticarcillin versus moxalactam and ticarcillin in febrile neutropenic patients. Arch Intern Med 1985;145:1083-8.

8. Bergeron MG, Mendelson J, Harding GK, et al. Cefaperazone compared with ampicillin plus tobramycin for severe biliary tract infections. Antimicrob Agents Chemother 1988;32:1231-6.

9. Mandell LA, Bergeron MG, Ronald AR, et al. Once daily therapy with ceftriaxone compared with daily multiple dose therapy with cefotaxime for serious bacterial infections. A randomized double blind study. J Infect Dis $1989 ; 160 ; 433-41$.

10. Saginur R, Nicolle LE, Canadian Infectious Diseases Society Clinical Trials Study Group. Single doses compared with three days norfloxacin for treatment of uncomplicated urinary infection in women. Arch Intern Med. (In press)

11. Navas L, Robinson J, de Carvalho V, Wang E, the Canadian Pediatric Clinical Trials Network. Outcome of RSV infections in Canadian children. Presented at the 31st Interscience Conference on Antimicrobial Agents and Chemotherapy, Chicago, 1991. (Abst 712) 


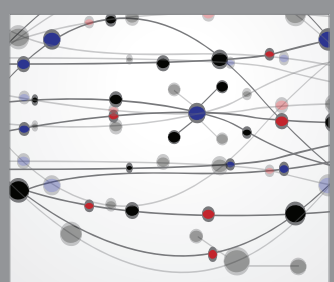

The Scientific World Journal
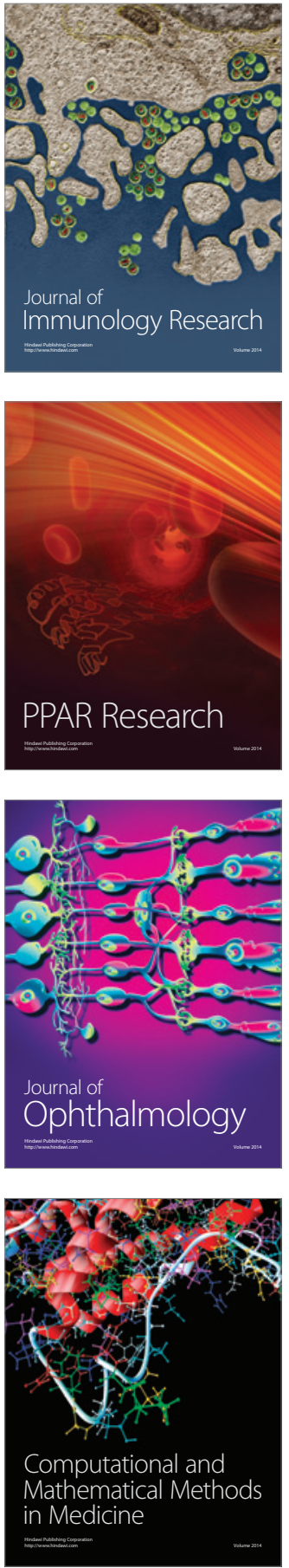

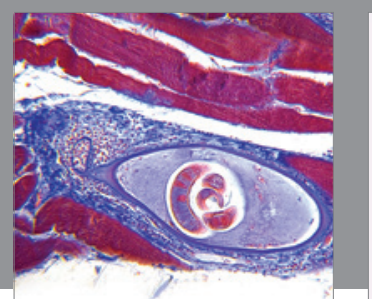

Gastroenterology Research and Practice

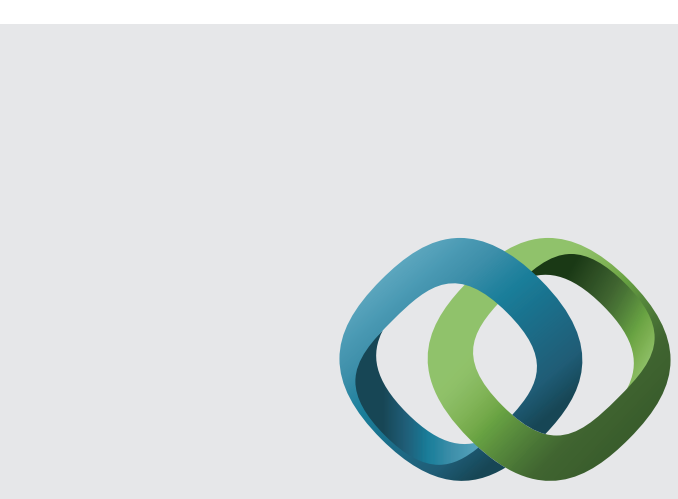

\section{Hindawi}

Submit your manuscripts at

http://www.hindawi.com
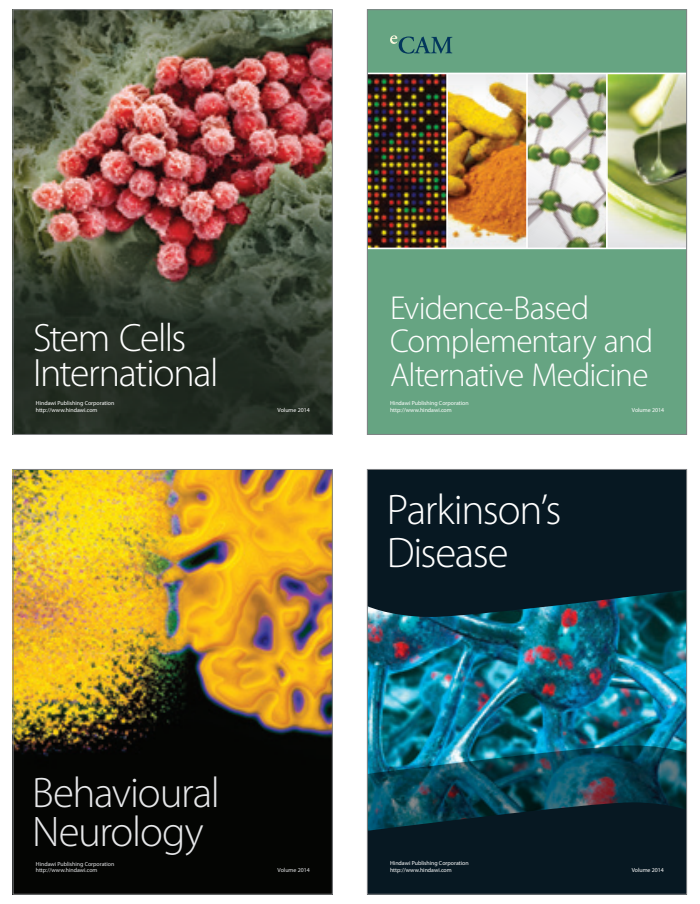
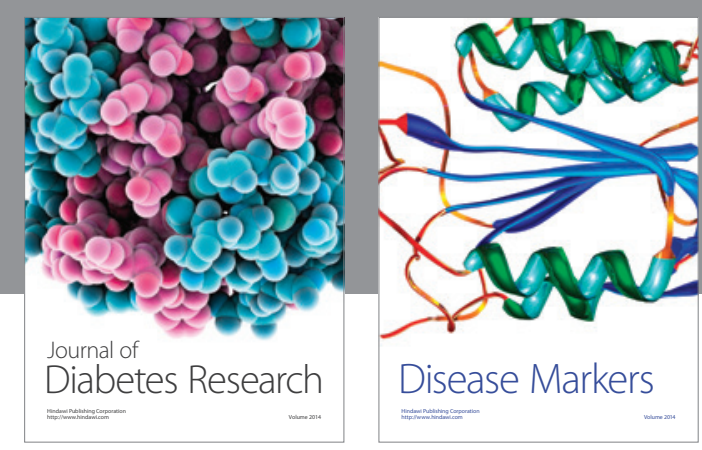

Disease Markers
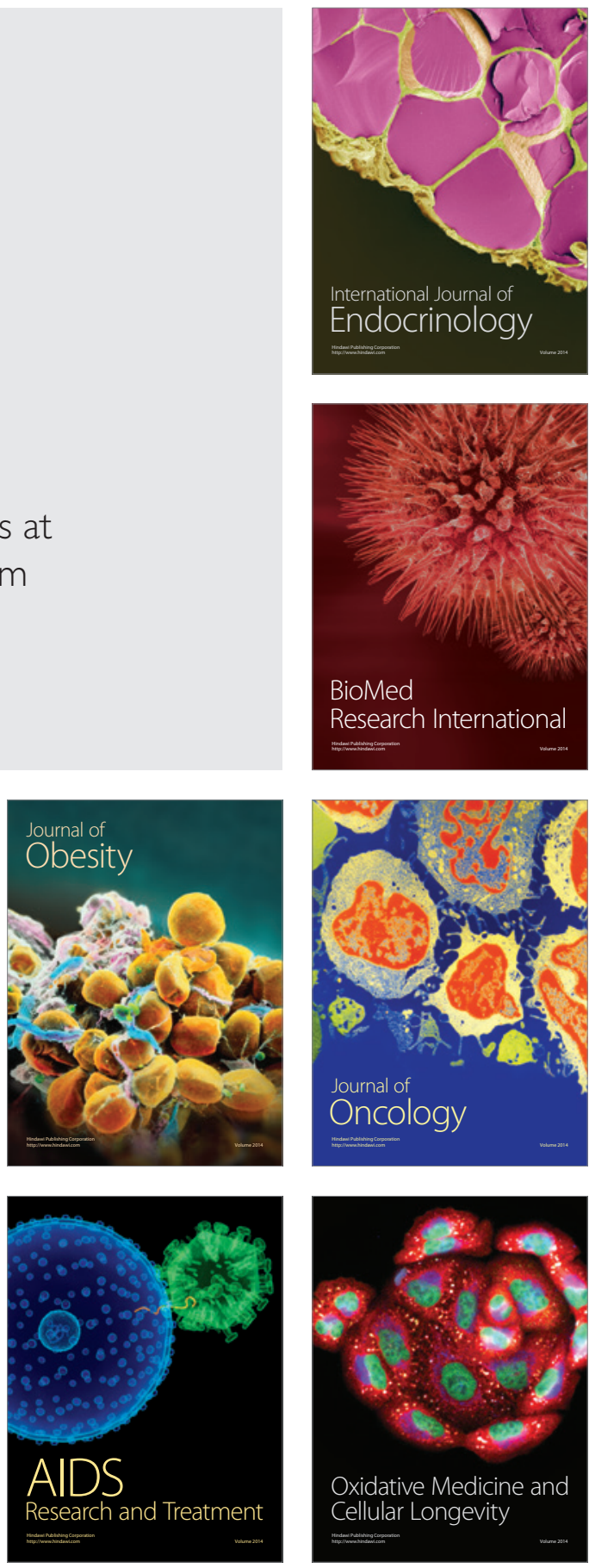